\title{
The meaning of computers to a group of men who are homeless.
}

\author{
Kathleen Swenson Miller \\ Thomas Jefferson University \\ Stacey Bunch-Harrison \\ Resources for Human Development \\ Brett Brumbaugh \\ Resources for Human Development \\ Rekha Sankaran Kutty \\ Horizon House \\ Kathleen FitzGerald \\ Manor Care
}

Follow this and additional works at: https://jdc.jefferson.edu/otfp

Part of the Occupational Therapy Commons

Let us know how access to this document benefits you

\section{Recommended Citation}

Miller, Kathleen Swenson; Bunch-Harrison, Stacey; Brumbaugh, Brett; Kutty, Rekha Sankaran; and FitzGerald, Kathleen, "The meaning of computers to a group of men who are homeless." (2005). Department of Occupational Therapy Faculty Papers. Paper 51.

https://jdc.jefferson.edu/otfp/51

This Article is brought to you for free and open access by the Jefferson Digital Commons. The Jefferson Digital Commons is a service of Thomas Jefferson University's Center for Teaching and Learning (CTL). The Commons is a showcase for Jefferson books and journals, peer-reviewed scholarly publications, unique historical collections from the University archives, and teaching tools. The Jefferson Digital Commons allows researchers and interested readers anywhere in the world to learn about and keep up to date with Jefferson scholarship. This article has been accepted for inclusion in Department of Occupational Therapy Faculty Papers by an authorized administrator of the Jefferson Digital Commons. For more information, please contact: JeffersonDigitalCommons@jefferson.edu. 


\title{
The Meaning of Computers to a Group of Men Who Are Homeless
}

\author{
Kathleen Swenson Miller, Stacey Bunch-Harrison, \\ Brett Brumbaugh, Rekha Sankaran Kutty, \\ Kathleen FitzGerald
}

The purpose of this pilot study was to explore the experience with computers and the meaning of computers to a group of homeless men living in a long-term shelter. This descriptive exploratory study used semistructured interviews with seven men who had been given access to computers and had participated in individually tailored occupation based interventions through a Work Readiness Program. Three themes emerged from analyzing the interviews: access to computers, computers as a bridge to life-skill development, and changed self-perceptions as a result of connecting to technology. Because they lacked computer knowledge and feared failure, the majority of study participants had not sought out computers available through public access. The need for access to computers, the potential use of computers as a medium for intervention, and the meaning of computers to these men who represent the digital divide are described in this study.

Swenson Miller, K., Bunch-Harrison, S., Brumbaugh, B., Kutty, R. S., \& FitzGerald, K. (2005). The meaning of computers to a group of men who are homeless. American Journal of Occupational Therapy, 59, 191-197.

Kathleen Swenson Miller, PhD, OTR/L, is Assistant Professor, Department of Occupational Therapy, Jefferson College of Health Professions, Thomas Jefferson University, 130 South 9th Street, Suite 810, Philadelphia, Pennsylvania 19107; Kathleen.Swenson-Miller@ jefferson.edu

Stacey Bunch-Harrison, MS, OTR/L, is Coordinator of Specialized Services, Resources for Human Development, Philadelphia, Pennsylvania.

Brett Brumbaugh, MS, OTR/L, is Occupational Therapist, Resources for Human Development, Philadelphia, Pennsylvania.

Rekha Sankaran Kutty, MS, OTR/L, is Occupational Therapist, Horizon House, Philadelphia, Pennsylvania.

Kathleen FitzGerald, MS, OTR/L, is Occupational Therapist, Manor Care, Philadelphia, Pennsylvania.
Eor most Americans, computer and Internet use have become interwoven into The fabric of everyday life. However, a digital divide in computer access and skills exists for many of the underserved adults with whom occupational therapists work. An extensive needs assessment of a new transitional housing program for persons who are homeless revealed that the residents' top priority was having access to computers and developing basic computer skills (Swenson Miller, Cornman-Levy, Rose, Lyons, \& Damani, 2000). Over 3 years, this unmet need became a focus of occupational therapy in three housing programs in Philadelphia for homeless persons.

Occupational therapists took the lead in assisting residents to develop computer labs and develop policy and procedures for their use within the housing programs, as part of development of life-skill and work readiness programs. Once the computer labs were operational within the three housing programs, the residenttherapist teams frequently used computers as a medium and the computer lab as an intervention environment to achieve client-centered goals. Yet little is known of the usage and meaning of computers to individuals who are homeless. Using semistructured interviews with a group of homeless men who had graduated from a work readiness program, the authors examined the men's experience with and perception of computers before and after their exposure to computers in a work readiness program.

\section{Literature Review}

\section{The Homeless Population}

A person who is homeless is currently defined by the federal government as an individual who does not have a regular nighttime residence and lives in a shelter 
designed to provide temporary living accommodations OR lives in a public or private place not designed as a regular sleeping accommodation for human beings (National Coalition for the Homeless, 2002). Homelessness can be described as a poverty issue, housing issue, job-skills issue, and health care issue. Therefore, integrating the efforts of housing, employment, education, health, and mental health services is important because of the complexity of homelessness. An ongoing epidemiological analysis of homelessness found between 444,000 to 842,000 people used homeless assistance services at one point in 1996, the last best national count of homelessness in the United States (Burt, 2002). In 1996, the national homeless population was composed of $61 \%$ single men, $15 \%$ single women, $15 \%$ of households with children, and $9 \%$ adults living with another adult but no children. The monthly median income of a homeless person in 1996 was $\$ 300$. Twenty to $30 \%$ of homeless individuals had no income (Burt).

Health problems, mental illness, and substance abuse are significant issues for many persons who are homeless. Forty-six percent report chronic physical conditions (Burt, 2002). An estimated 15 to $20 \%$, perhaps up to $30 \%$, of the homeless population has serious and persistent mental illness such as schizophrenia or bipolar disorder (Toro \& Warren, 1999). Substance abuse is a health problem for 34 to $60 \%$ of single adults who are homeless. Twenty to $30 \%$ of the homeless population has a dual diagnosis of substance abuse and serious mental illness (Burt; National Coalition for the Homeless, 2002; Toro \& Warren). The National Coalition for the Homeless reports that up to $50 \%$ of homeless women and children were fleeing domestic violence. The multiple issues related to homelessness require multifaceted interventions.

Many advocates for the homeless feel that stable housing is the primary need of homeless persons. Additional types of support are also important: economic support; lifeskills training that includes budgeting and household management; educational and work-skill development; and attention to any health, social, emotional, or domestic issues that were part of a person's homelessness trajectory (Burt, 2002; Morse, Calsyn, Allen, Tempelhoff \& Smith, 1992; Toro \& Warren, 1997). In a recent longitudinal study of homelessness, homeless adults rated transportation, medical and dental treatment, health care information, and job training as important as housing for ending their homelessness (Acosto \& Toro, 2000).

Finding solutions to break the cycle of homelessness is important for the health, dignity, and autonomy of homeless individuals. The societal cost of homelessness is reflected in public dollars that provide services to the homeless: shelter services, city jails, general medical and hospital services to treat unmanaged medical conditions, and psychiatric stays (Burt, 2002). When stable housing with support services is provided to address the issues of homeless persons with serious mental disabilities, health care dollars realize the greatest savings of all public service dollars (Culhane, Metraux, \& Hadley, 2002).

\section{The Digital Divide and Computers}

Underserved populations typically represent the digital divide, which has been described by the U.S. Department of Commerce as one of America's foremost economic and civil rights issues. The digital divide is defined as "the divide between those with access to new technologies and those without" (U.S. Department of Commerce, 2000, p. 1). Persons least likely to lack access to computer resources include those who are low-income, less educated, minority, single-parent households, and have disabilities (National Telecommunications and Information Administration, 2002). To our knowledge, no published research has been done to explore the homeless and their access to computers.

Computers have not typically been found in the community programs that provide services to underserved adults who may have chronic mental illness, substance abuse issues, or disabilities. When access to technology and training in computers was provided, a study found that underserved populations could successfully use the technology to address their specific concerns (Bier, Gallo, Nucklos, Sherblom, \& Pennick, 1997). Research suggests that health promotion Web-based applications can improve health knowledge, attitudes, emotional well-being, and reduce the amount of unnecessary health care (Eng et al., 1998). However, the efficacy of computer skill development and Web-based applications with the homeless has not yet been studied.

\section{Occupational Therapy and Homelessness}

The occupational therapy literature addressed homelessness as early as 1995 . Since that time, literature has addressed issues of: program needs from an occupational therapy perspective (Camardese \& Youngman, 1996; Finlayson, Baker, Rodman, \& Herzberg, 2002; Herzberg \& Finlayson, 2001; Tryssenaar, Jones, \& Lee, 1999); policy issues affecting the role of occupational therapy (Mitchell \& Jones, 1997); posttraumatic stress disorder and life-skill deficits of homeless mentally ill women (Davis \& Kutter, 1998); the relationship between developmental delays and successful work experiences for homeless adolescents (Kannenberg \& Boyer, 1997); and shelter programs for homeless mothers and children (Stancliff, 1997). Kavanaugh and Fares (1995) suggested that occupational therapy helps homeless individuals 
improve their feelings of self-worth, increase their experience of success, and feelings of control. This study, building upon the occupational therapy literature stressing the need for systematic needs assessment and client-centered care, explored the concept of technology related to work and life skills of a group of men who were homeless.

\section{Computer Use as an Occupation}

Grogan (1994) examined the use of computers as an occupational therapy treatment modality, viewing computer use as a potentially powerful activity because of high societal value, adaptability, and gradability to meet a person's values and functional abilities. One case study described a computer intervention as a productive activity to be successful in engaging residents with mental illness for the reasons Grogan hypothesized (Stancliff, 1997).

Most occupational therapy literature related to computers has focused on assistive technology, computer-aided instruction, and management applications (Angelo \& Smith, 1993; Jarus, Shavit, \& Ratzon, 2000; McBain \& Renton, 1997; O’Leary, Mann, \& Perkash, 1991; Unsworth \& Townsend, 1997). This study explored the experience with and perception of computers by a population that represents the digital divide, homeless men.

\section{Methods}

\section{Study Design}

The investigators explored the following research questions with a group of seven men who had recently graduated from a long-term shelter work readiness program. What experience did the men have with computers prior to beginning the Work Readiness Program? How did they perceive computers before and after the Work Readiness Program? How did they perceive computers to be part of their future?

Because so little is known about the topic of this study, a descriptive exploratory design was selected, using semistructured interviews. The investigators developed and used a structured demographic and homelessness risk factor questionnaire as well as a "Meaning of Computers" semistructured questionnaire. A sample of the questions that were used are: "Before you entered this program, how did you feel about computers?"; "What do computers help you do now that you could not do before?"; and "Please tell me about any goals that you feel that you accomplished through the use of computers." This study did not explore Internet usage and perceptions, since Internet connection at the shelter was not available at the time of this study.

\section{Participants}

The study's seven adults were a convenience sample of men residing in long-term shelter beds of the largest men's shelter in a large urban community. Table 1 profiles the demographic and risk factors for homelessness of the study sample. The men were recruited from graduates of an 8-week work readiness program that had included computers as a medium for occupational therapy intervention. Eligibility criteria included ability to engage in a 30- to 60-minute interview, fluency in English, a minimum of 18 years of age, and abstention from drugs and alcohol. An institutional review board approved the study.

\section{Data Collection and Analysis Techniques}

The men were individually interviewed in a private space by one of four interviewers. The interviews were audiotaped and transcribed. Quantitative information from the closed-ended questions of the interviews was summarized as descriptive data. In an effort to begin to understand homeless men's perceptions of computers, the transcripts were analyzed using Strauss' open conceptual coding methods of thematic analysis (Strauss, 1987). Three of the investigators independently identified the themes regarding perceptions of computers identified throughout the transcripts, discussed the emerging themes, and resolved any thematic discrepancies. Line-by-line coding of the transcripts was done using these themes, reanalyzing and collapsing redundant categories over a 4-week period of time. The investigators worked towards consensus in capturing the themes. The purpose of this study was not to develop a grounded theory of the men's experiences, but instead to conduct a preliminary thematic analysis, consistent with an exploratory study.

Table 1. Demographic and Risk Factor for Homeless Profile of Study Participants

\begin{tabular}{lc}
\hline Characteristics & $N=7$ \\
\hline Age, mean (range) & $35(21-47)$ \\
Race & \\
$\quad$ Black & $7(100 \%)$ \\
$\quad$ White & 0 \\
Number of months in shelter, mean (range) & $2.43(2-4)$ \\
Number of months homeless, mean (range) & $10(2-36)$ \\
Years of education, mean (range) & $12(9-16)$ \\
History of special education in school & $2(29 \%)$ \\
Self-rating of health (1 = excellent, 5 = poor), mean (range) & $2.86(1-5)$ \\
Have a health condition that affects ability to work & $2(29 \%)$ \\
Have received previous help with drugs & $6(86 \%)$ \\
Have received previous help with alcohol & $4(57 \%)$ \\
Have received previous help with psycho-emotional issue & $5(71 \%)$ \\
Have a criminal history & $7(100 \%)$ \\
\hline
\end{tabular}




\section{Results}

Three themes emerged from the data: access to computers; computers as a bridge to life-skill development; and changed self-perceptions as a result of connecting with technology.

\section{Access to Computers}

Before the Work Readiness Program. Four of the 7 participants had not had access to computers prior to the Work Readiness Program. None of the participants had owned a computer. The men who previously did not have access to computers had not sought out public access to computers such as public libraries. Several men stated they had not known what to do with computers before the Work Readiness Program - they did not even know how to turn on a computer. One participant described his frustration with his lack of computer knowledge by saying "[I] wanted to blow computers up because . . they [previous employer] all wanted us to go back to school [auto mechanics] and learn about the computers and that really upset me" (participant 3). Participants who felt they did have access to computers identified a friend, community college, the public library, or a mother's home as sources of access. The participant with the most experience with computers gained his knowledge about computers through Job Corps, not through regular public schools. For the 3 participants with access to computers, usage ranged from daily to once a month. Prior to the Work Readiness Program, only 1 participant had skill in multiple software applications, such as Word, Excel, and PowerPoint.

After the Work Readiness Program. After their computer exposure in the Work Readiness Program, three men stated that purchase of a computer was a high priority for them. Six men felt they would use the public library as their access point. Never believing before the Work Readiness Program that he would go to college "in a million years," 1 participant planned to use computer facilities at the local community college (participant 5).

\section{Bridge to Life-Skill Development}

The men described the computer as a relevant bridge for building life skills. As part of the Work Readiness Program, the men negotiated with the occupational therapist individual work and life-skills goals felt were important to becoming self-sufficient. Using the computer frequently as a medium and the computer lab as a work environment, the occupational therapist coached the men towards successful accomplishment of these goals. Six of the seven men reported that the computer was a tool that enabled them to work toward personal goals such as managing stress, man- aging time, doing research through the Internet on topics of importance, organizing personal documents, writing resumes, focusing thinking, and dealing with fear of new skills. The men used the computer to play games, participate in creative expression activities through writing poetry and letters, develop literacy skills on a level where they could be successful, and learn basic math concepts. One participant spoke to the gaps in basic skills of many homeless people. "The majority of people here are missing a lot of basic skills and math, reading, computers, stuff, you know" (participant 2).

In order of frequency, the men planned to use a computer once they left the shelter for: healthy leisure skills (4) by playing computer games, listening to music, obtaining sports schedules; developing a business (3) and maintaining business records; personal budgeting (3); managing time (2); developing work skills, such as working in a hospital lab (1); communicating through e-mail (1); getting transportation schedules (1); journaling by keeping track of priorities, successes, and failures (1); researching career options (1); and identifying shopping discounts (1). Some of these uses implied Internet access.

Several activities of interest to the men involved use of the Internet. The occupational therapist had taken all participants to the public library on one occasion to demonstrate use of the Internet. When asked specifically about potential personal use of the Internet, the men cited uses that involved e-mail (3) and getting information about health issues, scholarships, and general questions (4). Other uses included discussion groups (1), job searching (1), games (1), shopping (1) and getting schedules (e.g., transportation) (1).

\section{Changing Perceptions of Self}

Self-efficacy in computer use. The men discussed their initial fear confronting computer technology. In reflection, the participants were proud of their ability to overcome their fear in order to learn new valued skills.

I thought it was hard at first when I first started. I was kinda hesitant to learn, once I was forced to...[it was] nothing. I am finding out that one of my problems is having fear, doing something that you want to do and getting to it, and then having to master it. It's a problem. It takes courage (participant 5).

The men's confidence level in use of the computer consistently increased after their experience in the Work Readiness Program. Before the Work Readiness Program, 5 of the 7 participants had no confidence in using computers; two were somewhat confident. After completion of the Work Readiness Program, all 7 of the participants were extremely or very confident of their skills in computer use. 
Lifting self-expectations. The men described how the use of computers addressing their personal goals served as an intervention tool to raise their self-esteem: "[Computers] lifted my self-esteem, gave me a positive outlook. Now I can do a number of things on computers. . . . [Computers] raised my level of expectation of myself" (participant 3). One man spoke of the motivation provided by having access and gaining skill in computers: "They'll just be turning [the computer] on, like they're turning on a light" (participant 2). Men spoke of "getting in touch with their abilities" (participant 7) and gaining confidence while "doing something positive" (participant 6) for themselves, thus raising self-expectations. Working with computers was generally a positive experience for the men. One participant said, "Basically [computers] just makes me happy" (participant 3). The men's positive experience in learning computer skills appeared to go beyond building self-confidence in computer use to having a generalized impact on lifting their self-esteem.

Connecting with society. The men realized that computer technology is a part of the infrastructure of much of American society today, impacting the way we do our daily occupations ranging from banking to shopping to work opportunities. One participant summarized this theme: "Computers are like a move, changing man" (participant 5). One participant described how he saw technology as a way to reconnect to society.

If you don't get on now, you'll be left behind ... it'll be so much more information that you'll need to catch up on, and ... you may get frustrated ... so it would be wise to take advantage of any course, especially in a facility like this, to be taught, even the basics, and once you got a good teacher, a person that is really interested, that [homeless] person won't turn back" (participant 7).

Another participant talked about how computers can connect people through a common understanding and experience: "Computers are really good, like a stepping stone to getting back into society cause sometimes ... I don't know how to put it . . something that connects everybody is, like, the computer" (participant 5). Their positive experience with computers gave them a sense of stepping back into society.

Following an experience in a work readiness program, seven men discussed their experience and perceptions of computers that had been used in accomplishing client-generated work and life-skill goals. The primary themes that emerged included: access to computers for a population that represents the digital divide; viewing computers as a bridge to approaching life-skill development; and changes in the men's self-efficacy, self-esteem, and sense of reconnecting with society.

\section{Discussion}

By enabling access and graded learning to computers, the occupational therapist through a work readiness program provided men who are homeless an introduction to technology. These men, representing the digital divide, had no or limited exposure to technology, except for 1 study participant. The men had not explored this technology on their own through public access programs such as the public library because of fear of technology and lack of confidence in learning a skill they perceived to be intimidating. The study participants required a graded introduction to computers by a professional who comprehended their personal resources, limitations, and goals.

Each participant reported that his self-efficacy in use of computers improved by the end of the 8-week experience. All of the participants valued computers sufficiently to have plans to either purchase a computer or use public access to computers, such as the public library. This suggests the men came not only to value computers, but the role computers could play in their personal rebuilding plan to rejoin mainstream society.

Computers served as a medium for the men to achieve client-centered goals and develop confidence in learning new skills. Using a computer, occupational therapists can readily tailor interventions to address client goals and grade computer related activity for success. Grogan (1994) discussed how computers can afford a range of opportunities for adaptation and gradability to accomplish individual goals. The men in this study used the computer to address many of the areas of their lives that they were rebuilding, such as preparing to enter the working world, building healthy leisure activities, and planning better time management. The men's goals were consistent with traditional societal values of work, self-sufficiency, and striving towards healthy living, a context from which chronically homeless persons are frequently disenfranchised.

The theme of "changing perceptions of self" included the concept of lifting self-expectations, describing the process of gaining a new skill as a medium for psychological transformation. Gage and Polatajko (1994) discuss the relationship between self-efficacy, self-esteem, and occupational performance. Bier et al. (1997) described a sense of empowerment gained in low-income families who were introduced to computers and the Internet for the first time. The empowerment literature views the importance of self-efficacy and its relationship to an internal locus of control, a sense of mastery and increased ability to act as part of the empowerment process (Gutierrez, 1990). For these men, seeing themselves as capable individuals with a vision of a life other than homelessness is pivotal to their rebuilding process. 
Qualitative studies show that homelessness involves more than a lack of stable housing, particularly for those who are chronically homeless. The loss of identity, selfworth, and self-efficacy have been cited as a common theme that occurs with the phenomenon of homelessness (Buckner, Bassuk, \& Zima, 1993). This study suggests that the men credited successful use of computers in lifting their expectations of themselves, improving their self-esteem, and assisting in much needed development of transferable skills that they could use in the future within their personal and work lives. As part of the occupational therapy intervention, the occupational therapist routinely provided a forum for the men to identify the skills and feelings of accomplishment so this process of transformation could be applied to new situations.

Changed perceptions of self included "connecting to society," reflecting Grogan's (1994) discussion of the high societal value placed on computers. In a study that examined the impact of computer and Internet use with lowincome families, participants reported that they no longer saw themselves as inferior to those they converse with on the Internet who might have more education, money, or social standing (Bier et al., 1997). The chronically homeless population can be disconnected from the values of society, so this feeling of a way to be connected to larger society is important for this population. Homelessness has been described as an event, but also a process that entails a great deal of loss. Boydell, Goering, and Morrell-Bellai (2000), through use of a phenomenological approach, describe the struggle of homeless persons as they strive to have valued lives and selves. Homelessness creates identity problems whereby the individual's former positive identity is preserved, present identity is in crisis, and only glimpses of a future identity can be gleaned from their present situation. The participants in this study discussed how gaining competence in computers with a caring individual who enabled success offered them a way to step back into mainstream society and lifted their expectations of themselves.

\section{Implications for Occupational Therapists}

The study supports the need for occupational therapists to advocate for access to computers and teach basic computer skills to underserved populations. Several of the investigators, who have worked extensively with the homeless population, had to work through administrative barriers in order to acquire computer access for this population. Initially, program administrators did not view computer access and skills as a priority for the homeless population. Yet, an extensive needs assessment from a group of homeless individuals stressed their strong interest in becoming connected to today's technology (Swenson Miller et al., 2000). A second assumption by administrators was that public access to computers is available through public libraries and would be used if computers were a priority to the population. Yet, 6 of 7 study participants reported that they would not have sought out computers through this public access because of lack of computer knowledge and fear of failure. A third assumption by administrators was that providing access to computers is sufficient, disregarding the need for graded skill building. This study described how developing computer skills around personal goals and grading computer skill learning were critical to building the men's feeling of competence.

Occupational therapists are well-suited to work with this underserved population because of their professional knowledge skill set. The activity of computer use is ripe for tailoring interventions for many underserved populations, providing a form of societal participation that is felt to be important to any disenfranchised population. Occupational therapists need to explore ways to provide computer and Internet access for underserved populations through research and networking with community programs (www. DigitalDivideNetwork.org).

\section{Acknowledgments}

This study was completed in partial fulfillment of requirements for a master's degree in occupational therapy from Thomas Jefferson University by the second through fifth authors. Work with the homeless population by the first two authors has been supported by funding from the U.S. Department of Health and Human Services, Bureau of Health Professions, and the City of Philadelphia Office of Emergency Shelter Services. The investigators are especially grateful to the men who participated in this study.

\section{References}

Angelo, J., \& Smith, R. O. (1993). An analysis of computer-related articles in occupational therapy periodicals. American Journal of Occupational Therapy, 47, 25-29.

Acosta, O., \& Toro, P. A. (2000). Let's ask the homeless people themselves: A needs assessment based on a probability sample of adults. American Journal of Community Psychology, 28, 343-366.

Bier, M., Gallo, M., Nucklos, E., Sherblom, S., \& Pennick, M. (1997). Personal empowerment inthe study of home Internet use of low-income families. Journal of Research in Computer Education, 30, 107-121.

Boydell, K. M., Goering, P., \& Morrell-Bellai, T. L. (2000). Narratives of identity: Representation of self in people who are homeless. Qualitative Health Research, 10, 26-38.

Buckner, J. C., Bassuk, E. L., \& Zima, B. T. (1993). Mental 
health issues affecting homeless women: Implications for intervention. American Journal of Orthopsychiatry, 63, 385-399.

Burt, M. R. (2002, November). Revisiting the epidemiology of homelessness. Paper presented at the meeting of the American Public Health Association, Philadelphia, PA.

Camardese, M. B., \& Youngman, D. (1996). H.O.P.E.: Education, employment, and people who are homeless and mentally ill. Psychiatric Rehabilitation Journal, 19, 45-56.

Culhane, D. P., Metraux, S., \& Hadley, T. (2002). Public service reductions associated with placement of homeless persons with severe mental illness in supportive housing. Housing Policy Debate, 13, 107-163.

Daskal, J. (1998). In search of shelter: The growing shortage of affordable rental housing. Washington, DC: Center on Budget and Policy Priorities.

Davis, J., \& Kutter, C. J. (1998). Independent living skills and posttraumatic stress disorder in women who are homeless: Implications for future practice. American Journal of Occupational Therapy, 52, 39-44.

Eng, T. R., Maxfield, A., Patrick, K., Deering, M. J., Ratzan, S. C., \& Gustafson, D. H. (1998). Access to health information and support: A public highway or a private road? JAMA, 280, 1371-1375.

Finlayson, M., Baker, M., Rodman, L., \& Herzberg, G. (2002). The process and outcomes of a multimethod needs assessment at a homeless shelter. American Journal of Occupational Therapy, 56, 313-321.

Gage, M., \& Polatajko, H. (1994). Enhancing occupational performance through an understanding of perceived self-efficacy. American Journal of Occupational Therapy, 48, 452-461.

Grogan, G. (1994). The personal computer: A treatment tool for increasing sense of competence. Occupational Therapy in Mental Health, 12, 47-61.

Gutierrez, L. (1990). Working with women of color: An empowerment perspective. Social Work, 35, 149-153.

Herzberg, G., \& Finlayson, M. (2001). Development of occupational therapy in a homeless shelter. Occupational Therapy in Health Care, 13, 133-147.

Jarus, T., Shavit, S., \& Ratzon, N. (2000). From hand twister to mind twister: Computer-aided treatment in traumatic wrist fracture. American Journal of Occupational Therapy, 54, 176-182.

Kannenberg, K., \& Boyer, D. (1997). Occupational therapy evaluation and intervention in an employment program for homeless youths. Psychiatric Services, 48, 631-633.
Kavanaugh, J., \& Fares, J. (1995). Using the model of human occupation with homeless mentally ill clients. British Journal of Occupational Therapy, 58, 420-422.

McBain, K., \& Renton, L. B. (1997). Computer-assisted cognitive rehabilitation and occupational therapy. British Journal of Occupational Therapy, 60, 199-204.

Mitchell, H., \& Jones, D. (1997). Homelessness: A review of the social policy background and the role of occupational therapy. British Journal of Occupational Therapy, 60, 315-319.

Morse, G., Calsyn, R. J., Allen, G., Tempelhoff, B., \& Smith, R. (1992). Experimental comparison of three treatment programs for homeless mentally ill people. Hospital and Community Psychiatry, 43, 1005-1010.

National Coalition for the Homeless. (2002, September). Who is homeless? Washington, DC: Author.

National Telecommunications and Information Administration. (2002, February). A nation online: How Americans are expanding their use of the Internet. Retrieved June 7, 2004, from http://www.ntia.doc.gov/ntiahome/dn/html

O'Leary, S., Mann, C., \& Perkash, I. (1991). Access to computers for older adults: Problems and solutions. American Journal of Occupational Therapy, 45, 636-642.

Stancliff, B. L. (1997, November). OT uses computers to reach mental health clients. OT Practice, 2, 87-90.

Strauss, A. (1987). Qualitative analysis for social sciences. Cambridge, England: Cambridge University Press.

Swenson Miller, K., Cornman-Levy, D., Rose, M., Lyons, K., \& Damani, S. (2000, November). Perception of needs identified through focus groups in urban homeless shelters and transitional housing programs. Poster session presented at the annual meeting of the American Public Health Association, Boston, MA.

Toro, P. A., \& Warren, M. G. (1999). Homelessness in the United States: Policy considerations. Journal of Community Psycholo$g y, 27,119-136$.

Tryssenaar, J., Jones, E., \& Lee, D. (1999). Occupational performance needs of a shelter population. Canadian Journal of Occupational Therapy, 66, 188-195.

U.S. Department of Commerce. (2000, October). Falling through the net: defining the digital divide. Retrieved August 22, 2002, from http://www.ntia.doc.gov/ntiahome/fttn99/ introduction.html.

Unsworth, C. A., \& Townsend, M. C. (1997). Occupational therapists' skills and attitudes regarding use of computers and assistive technology. Occupational Therapy International, 4, $52-65$. 